\title{
Characteristics of traumatic brain injury during Operation Enduring Freedom-Afghanistan: a retrospective case series
}

\author{
Parantap Patel, BS, Davis Taylor, MD, and Min S. Park, MD \\ Department of Neurological Surgery, University of Virginia Health System, Charlottesville, Virginia
}

Traumatic brain injury (TBI) is a significant cause of morbidity and mortality, especially among members of the armed services. Injuries sustained in the battlefield are subject to different mechanisms than those sustained in civilian life, particularly blast and high-velocity injury. Due to the unique nature of these injuries and the challenges associated with battlefield medicine, surgical interventions play a key role in acute management of TBI. However, the burden of chronic disease posed by TBI is poorly understood and difficult to investigate, especially in the military setting. The authors report the case logs of a United States Navy neurosurgeon, detailing the acute management and outcomes of 156 patients sustaining TBI between November 2010 and May 2011 during the war in Afghanistan. By demographics, more than half of the patients treated were local nationals. By mechanism of injury, blunt trauma (40.4\%) and explosive injury (37.2\%) were the most common contributors to TBI. Decompressive craniectomies (24.0\%) and clot evacuations (14.7\%) were the procedures most commonly performed. Nearly one-quarter of patients were transferred to receive further care, yet only 3 patients were referred for rehabilitative services. Furthermore, the data suggest that patients sustaining comorbid injuries in addition to TBI may be predisposed to worse outcomes. Improvements in documentation of military patients may improve knowledge of TBI and further identify potential variables or treatments that may affect prognosis. The increased survivability from TBI also highlights the need for additional research expenditure in the field of neurorehabilitation specifically.

https://thejns.org/doi/abs/10.3171/2019.8.FOCUS19493

KEYWORDS traumatic brain injury; blast injury; military medicine; neurorehabilitation; decompressive craniectomy; comorbid injury

$\mathrm{T}$ RAUMATIC brain injury (TBI) is a leading cause of morbidity and mortality among young adults. ${ }^{16}$ Over the last 2 decades in particular, blast injury related to wartime or armed conflict has become a leading cause of TBI, with approximately 383,000 armed service members sustaining TBI over this time period (https:// dvbic.dcoe.mil/dod-worldwide-numbers-tbi). Although severe TBI may be managed acutely in the hospital to reduce mortality, the long-term morbidity can be equally devastating and manifest as cognitive impairment, neurodegenerative disease, posttraumatic epilepsy, stroke, and psychiatric illness, among a host of other complications. ${ }^{35}$ When compared to the civilian population, TBI encountered in a combat hospital is often subject to different mechanisms due to the high incidence of blast injury. ${ }^{33}$ We report the military and civilian TBI case logs of a single United
States Navy (USN) neurosurgeon (M.S.P.) while on deployment in Afghanistan during the military surge in 2010 to 2011. At the time of deployment, 2 United States Armed Forces neurosurgeons were stationed in Afghanistan-one in the northern half of the combat theater and the other in the southern half at Kandahar Airfield. The neurosurgeon at Kandahar Airfield (M.S.P.) was responsible for all neurosurgical care in the southern half of the combat theater during the deployment.

\section{Methods}

Following approval by the Joint Combat Casualty Research Team at the Bagram Airfield, Afghanistan, the military and civilian case logs of a single USN neurosurgeon from his deployment to Kandahar, Afghanistan, from No- 
TABLE 1. Demographics and injury characteristics of 156 patients with TBI

\begin{tabular}{|c|c|c|}
\hline Characteristic & No. of Cases & $\%$ of Total \\
\hline \multicolumn{3}{|l|}{$\operatorname{Sex}(n=156)$} \\
\hline Male & 139 & $89.1 \%$ \\
\hline Female & 17 & $10.9 \%$ \\
\hline \multicolumn{3}{|l|}{ Nationality/wartime affiliation $(n=156)$} \\
\hline Local national & 102 & $65.4 \%$ \\
\hline Afghan National Army & 21 & $13.5 \%$ \\
\hline American national \& ISAF & 20 & $12.8 \%$ \\
\hline Detainee & 6 & $3.8 \%$ \\
\hline Afghan National Police & 4 & $2.6 \%$ \\
\hline Contractor & 2 & $1.3 \%$ \\
\hline Pakistani contractor & 1 & $0.6 \%$ \\
\hline \multicolumn{3}{|l|}{ Mechanism of TBI $(n=156)$} \\
\hline Blunt trauma & 63 & $40.4 \%$ \\
\hline Explosive injury & 58 & $37.2 \%$ \\
\hline Penetrating low velocity & 22 & $14.1 \%$ \\
\hline Penetrating high velocity & 7 & $4.5 \%$ \\
\hline Other & 6 & $3.8 \%$ \\
\hline \multicolumn{3}{|l|}{ Comorbid injuries $(n=64)^{*}$} \\
\hline Laceration & 27 & $42.2 \%$ \\
\hline Fracture & 17 & $26.6 \%$ \\
\hline Globe injury & 12 & $18.8 \%$ \\
\hline Injury requiring exploratory laparotomy & 7 & $10.9 \%$ \\
\hline Amputation & 7 & $10.9 \%$ \\
\hline Gastrointestinal injury & 5 & $7.8 \%$ \\
\hline Pulmonary injury & 3 & $4.7 \%$ \\
\hline Injury requiring incision \& drainage & 3 & $4.7 \%$ \\
\hline Paraplegia or quadriplegia & 2 & $3.1 \%$ \\
\hline Vascular injury & 2 & $3.1 \%$ \\
\hline Other & 9 & $14.1 \%$ \\
\hline
\end{tabular}

ISAF = International Security Assistance Force.

Except for "other," data are presented in descending order with regard to number of cases. Percent of total was calculated as number of cases divided by number of patients.

${ }^{*}$ Note that 21 of the 64 patients sustained more than one comorbid injury.

vember 2010 to May 2011 were retrospectively reviewed. Demographic information including sex, date of birth, and nationality or wartime affiliation was prospectively entered by the USN neurosurgeon at the time of consultation. Injury-specific information, such as mechanism of injury, neurological examination findings, Glasgow Coma Scale (GCS) score at admission, accompanying injuries, and mode of arrival as well as operations and procedures performed were cataloged. GCS score at discharge and status at discharge were also cataloged when available. Data were then de-identified, retrospectively reviewed, and codified to allow statistical analysis.

Due to the wide array of mechanisms, injuries were sorted into 1 of 5 categories: blunt trauma (motor vehicle accident, fall); explosive injury (blast injury, explosive missile injury, improvised explosive device); penetrating low-velocity injury (handgun injury, shrapnel, no exit wound); penetrating high-velocity injury (rifle injury, exit wound present); and other injury. These categories were compiled according to well-described mechanisms of combat injury, particularly differences in wounds sustained between explosive, penetrating low-velocity injury, and penetrating high-velocity injury. ${ }^{15,31}$ Clinical information including GCS score and pupillary status (reactive vs nonreactive) was recorded at the time of treatment, and the GCS score was later categorized into severe (GCS 3-4), moderate (GCS 5-12), and mild (GCS 13-15). The average GCS score across subjects was calculated for both admission and discharge, as was the change in average score between the 2 time points.

Further comparisons of admission and discharge GCS score, admission and discharge pupil nonreactivity, and discharge status were performed between patients sustaining a comorbid injury (any injury in addition to TBI) versus those sustaining no comorbid injuries. Similar comparisons were performed between patients sustaining severe comorbid injury versus all other patients. "Severe comorbid injury" was defined as fractures, vascular injuries, amputations, and injuries requiring exploratory laparotomy. Two-sample z-tests and chi-square contingency tables were performed for intergroup comparison.

\section{Results}

\section{Injury Characteristics}

Table 1 summarizes the demographics and injury characteristics of the patients with TBI, including sex, nationality or wartime affiliation, mechanism of TBI, and comorbid injuries. Of the 156 patients with TBI, $89.1 \%$ were male and $65.4 \%$ were local nationals. American nationals and International Security Assistance Forces comprised 20/156 patients (12.8\%). By mechanism, blunt trauma (40.4\%) and explosive injury (37.2\%) were the most common contributors to TBI, followed by penetrating low-velocity (14.1\%) and high-velocity (4.5\%) injury. Sixty-four patients $(41.0 \%)$ sustained comorbid injuries in addition to TBI. The most common injuries included 27 lacerations (42.2\%), 17 fractures (26.6\%), 12 globe injuries (18.8\%), 7 injuries requiring exploratory laparotomies (10.9\%), and 7 injuries requiring amputations (10.9\%), among several others.

\section{Procedures Performed Across Mechanisms of Injury}

Table 2 provides data for procedures performed in the acute postinjury period and a breakdown of the contributing mechanism of injury per procedure. Of the total 279 procedures performed, $67(24.0 \%)$ were craniectomies or skull fracture elevations. Blunt trauma (10.4\%) and explosive injury $(8.2 \%)$ were the major contributors to this procedure, followed by penetrating low-velocity injury (3.6\%), penetrating high-velocity injury (1.4\%), and other mechanisms $(0.4 \%)$. Clot evacuation was the second most common procedure performed $(41 ; 14.7 \%$ of all procedures), and significant contributors to the procedure included explosive injury (5.0\%), blunt trauma (4.7\%), and penetrating low-velocity injury (3.9\%). Other common procedures included ventriculoperitoneal shunt or external ventricular drain placement (12.5\% of all procedures), 
TABLE 2. Acute post-TBI procedures performed in 279 cases, with contributing mechanisms of injury

\begin{tabular}{|c|c|c|}
\hline Op \& Mechanism of Injury & No. of Ops & $\%$ of Total \\
\hline Craniectomy or skull fracture elevation & 67 & $24.0 \%$ \\
\hline Blunt trauma & 29 & $10.4 \%$ \\
\hline Explosive injury & 23 & $8.2 \%$ \\
\hline Penetrating low velocity & 10 & $3.6 \%$ \\
\hline Penetrating high velocity & 4 & $1.4 \%$ \\
\hline Other & 1 & $0.4 \%$ \\
\hline Clot evacuation & 41 & $14.7 \%$ \\
\hline Explosive injury & 14 & $5.0 \%$ \\
\hline Blunt trauma & 13 & $4.7 \%$ \\
\hline Penetrating low velocity & 11 & $3.9 \%$ \\
\hline Penetrating high velocity & 2 & $0.7 \%$ \\
\hline Other & 1 & $0.4 \%$ \\
\hline VPS or EVD & 35 & $12.5 \%$ \\
\hline Blunt trauma & 11 & $3.9 \%$ \\
\hline Explosive injury & 14 & $5.0 \%$ \\
\hline Penetrating low velocity & 6 & $2.2 \%$ \\
\hline Penetrating high velocity & 2 & $0.7 \%$ \\
\hline Other & 2 & $0.7 \%$ \\
\hline Spinal procedure & 30 & $10.8 \%$ \\
\hline Blunt trauma & 11 & $3.9 \%$ \\
\hline Explosive injury & 18 & $6.5 \%$ \\
\hline Penetrating low velocity & 1 & $0.4 \%$ \\
\hline Shrapnel or bone fragment removal & 19 & $6.8 \%$ \\
\hline Blunt trauma & 1 & $0.4 \%$ \\
\hline Explosive injury & 12 & $4.3 \%$ \\
\hline Penetrating low velocity & 4 & $1.4 \%$ \\
\hline Penetrating high velocity & 2 & $0.7 \%$ \\
\hline Craniotomy otherwise & 6 & $2.2 \%$ \\
\hline Blunt trauma & 3 & $1.1 \%$ \\
\hline Explosive injury & 3 & $1.1 \%$ \\
\hline Other op & 81 & $29.0 \%$ \\
\hline Blunt trauma & 34 & $12.2 \%$ \\
\hline Explosive injury & 29 & $10.4 \%$ \\
\hline Penetrating low velocity & 11 & $3.9 \%$ \\
\hline Penetrating high velocity & 4 & $1.4 \%$ \\
\hline Other mechanism & 3 & $1.1 \%$ \\
\hline
\end{tabular}

$E V D=$ external ventricular drain; VPS = ventriculoperitoneal shunt. Data are presented in descending order with respect to number of operations performed. Percent of total was calculated as number of operations divided by total number of operations.

spinal procedures $(10.8 \%)$, and shrapnel or bone fragment removals $(6.8 \%)$.

\section{Outcomes}

Table 3 summarizes patient outcomes following acute intensive care and provides pre-intensive care clinical data for comparison. On arrival to acute care, pupil reactivity was assessed in 100 patients, 33 of whom presented with nonreactive pupils (33.0\%). GCS scores were col-
TABLE 3. Patient outcomes following acute intensive care

\begin{tabular}{|c|c|c|}
\hline Variable & $\begin{array}{l}\text { No. of } \\
\text { Cases }\end{array}$ & $\begin{array}{l}\% \text { of } \\
\text { Total }\end{array}$ \\
\hline \multicolumn{3}{|l|}{ Arrival; pre-intensive care } \\
\hline Pupils nonreactive $(n=100)$ & 33 & $33.0 \%$ \\
\hline GCS score 3-4 $(n=139)$ & 2 & $1.4 \%$ \\
\hline GCS score $5-12(n=139)$ & 72 & $51.8 \%$ \\
\hline GCS score $13-15(n=139)$ & 65 & $46.8 \%$ \\
\hline GCS score, average $(n=139)$ & 11.0 & NA \\
\hline \multicolumn{3}{|l|}{ Discharge } \\
\hline Pupils nonreactive $(n=84)$ & 6 & $7.1 \%$ \\
\hline GCS score 3-4 $(n=108)$ & 2 & $1.9 \%$ \\
\hline GCS score $5-12(n=108)$ & 26 & $24.1 \%$ \\
\hline GCS score $13-15(n=108)$ & 59 & $54.6 \%$ \\
\hline GCS score, average $(n=108)$ & 13.3 & NA \\
\hline GCS score improvement, average $(n=101)$ & 1.5 & NA \\
\hline GCS score improved $(n=101)$ & 44 & $43.6 \%$ \\
\hline Transferred $(n=108)$ & 25 & $23.1 \%$ \\
\hline$P M \& R(n=108)$ & 3 & $2.8 \%$ \\
\hline Deceased $(n=133)$ & 3 & $2.3 \%$ \\
\hline \multicolumn{3}{|c|}{$\begin{array}{l}\text { NA = not applicable; PM\&R = physical medicine and rehabilitation. } \\
\text { GCS improvement was calculated in the subset of patients with a GCS score } \\
\text { recorded at both arrival and discharge ( } n=101) \text {. Final discharge destina- } \\
\text { tion and mortality were recorded using the total number of patients with } \\
\text { documented discharge ( } n=133 \text { ). Percent of total was calculated as number of } \\
\text { cases divided by total number of cases. }\end{array}$} \\
\hline
\end{tabular}

lected from 139 patients, with an average score of 11.0. At discharge, 84 patients were assessed for pupil reactivity, 6 of whom had nonreactive pupils (7.1\%). Discharge GCS scores were collected from 108 patients for an average score of 13.3. In the subset of 101 patients for whom GCS score was documented both at arrival and discharge, an average GCS score of 11.9 at arrival and 13.4 at discharge was observed-an average increase of 1.5. Forty-four patients in this subset experienced an improvement in GCS score, with an average score of 9.2 at arrival and 12.9 at discharge-an average increase of 3.7. Furthermore, of the 133 patients with a documented discharge, 108 had a GCS score recorded at that time; 25 of the 108 were transferred to another care center (23.1\%), and 3 were referred for physical medicine and rehabilitation $(2.8 \%)$. Of the aforementioned group of 133 patients, 3 died during their hospitalization (2.3\%).

Table 4 compares admission and discharge clinical data between patients sustaining comorbid injury versus those sustaining no comorbid injury and between patients sustaining severe comorbid injury versus all other patients. Sixty-four of the total 156 patients sustained comorbid injury, in addition to TBI (41.0\%). Of these 64 patients, 28 sustained severe comorbid injuries (43.8\%). Patients sustaining comorbid injuries presented with lower-although not statistically significant-GCS scores compared to those with no comorbid injuries $(10.3 \pm 3.7$ vs $11.4 \pm 3.8$; $\mathrm{p}=0.08)$, but were discharged with similar GCS scores $(13.4 \pm 2.8$ vs $13.3 \pm 3.0 ; p=0.89)$. This patient cohort was also observed to have a significantly higher incidence of 
TABLE 4. Comparison of pre-intensive care and post-intensive care clinical data of comorbid injury versus no comorbid injury cohorts, and of severe comorbid injury versus all other subjects

\begin{tabular}{|c|c|c|c|c|c|c|}
\hline \multirow[b]{2}{*}{ Variable } & \multicolumn{3}{|c|}{ Pre-Intensive Care } & \multicolumn{3}{|c|}{ Post-Intensive Care } \\
\hline & $\begin{array}{l}\text { Comorbid Injury, } \\
n=64\end{array}$ & $\begin{array}{l}\text { No Comorbid Injury, } \\
n=92\end{array}$ & $p$ Value & $\begin{array}{l}\text { Severe Comorbid } \\
\text { Injury, } n=28\end{array}$ & $\begin{array}{c}\text { Nonsevere \& No } \\
\text { Comorbid Injury, } n=128\end{array}$ & $\mathrm{p}$ Value \\
\hline GCS score at arrival, mean \pm SD & $10.3 \pm 3.7$ & $11.4 \pm 3.8$ & 0.08 & $11.0 \pm 3.7$ & $11.0 \pm 3.9$ & 0.96 \\
\hline GCS score at discharge, mean \pm SD & $13.4 \pm 2.8$ & $13.3 \pm 3.0$ & 0.89 & $13.1 \pm 3.4$ & $13.4 \pm 2.8$ & 0.76 \\
\hline Pupils nonreactive at arrival & $18 / 38(47.4 \%)$ & $15 / 62(24.2 \%)$ & $0.03^{*}$ & $6 / 16(37.5 \%)$ & $27 / 84(32.1 \%)$ & 0.77 \\
\hline Pupils nonreactive at discharge & $4 / 31(12.9 \%)$ & $2 / 53(3.8 \%)$ & 0.19 & $2 / 13(15.4 \%)$ & $4 / 71(5.6 \%)$ & 0.23 \\
\hline Transferred & $13 / 38(34.2 \%)$ & $12 / 70(17.1 \%)$ & 0.06 & $7 / 19(36.8 \%)$ & $18 / 89(20.2 \%)$ & 0.14 \\
\hline
\end{tabular}

The GCS score at arrival was assessed in 56 of 64 patients in the comorbid injury cohort; in 83 of 92 patients in the no comorbid injury cohort; in 23 of 28 patients in the severe comorbid injury cohort; and in 116 of 128 in the remaining patients. The GCS score at discharge was assessed in 38 of 64 patients in the comorbid injury cohort; in 69 of 92 patients in the no comorbid injury cohort; in 19 of 28 patients in the severe comorbid injury cohort; and in 88 of 128 in remaining patients. Incidences of pupil reactivity and final discharge destination are provided as number of cases divided by total number of respondents in each cohort. Statistical $p$ values generated from 2-sample z-tests and chi-square contingency tables are provided for intergroup comparisons.

${ }^{*}$ Statistically significant $(p<0.05)$.

pupil nonreactivity at arrival $(47.4 \%$ vs $24.2 \%$; $=0.03)$, but similar incidence of pupil nonreactivity at discharge $(12.9 \%$ vs $3.8 \%$; $\mathrm{p}=0.19)$. Furthermore, a higher incidence of transfer for additional care was observed in the comorbid injury cohort ( $34.2 \%$ vs $17.1 \%$; $p=0.06$ ), although this comparison did not reach statistical significance. Comparisons between the cohort sustaining severe comorbid injury and the remaining patient cohort showed no differences in the assessed variables.

\section{Discussion}

Across the ages, wartime mortality has seen significant improvements as battlefield medicine, and in particular triage, has improved the time to treatment. Innovations in rapid triage by the Napoleonic army under Dr. Dominique Larrey led to significant reductions in amputation mortality from a historical average well above $40 \%$ to nearly $25 \% .{ }^{18,25,26}$ Battlefield triage further improved over the next 2 centuries, first most significantly with the introduction of antibiotics, and again with the recognition of the "golden hour" policy, such that survivability from wartime injury today is now greater than $90 \%{ }^{4,13,19}$

In the most recent wars in Afghanistan and Iraq, survivability has improved so much that despite a $64 \%$ chance of double amputation following blast injury, mortality remains as low as $1.8 \%{ }^{23}$ However, this improvement in survivability has resulted in the greatest incidence of survivable TBI during the ongoing wars in Afghanistan and Iraq (https://dvbic.dcoe.mil/system/files/ tbi-numbers/worldwide-totals-2000-2018Q1-total_jun-212018_v1.0_2018-07-26_0.pdf). ${ }^{8,17,22,24,33}$ In the current series, $41 \%$ of patients had comorbid injuries in addition to head injury requiring neurosurgical intervention, yet only 3 patients died. But despite this remarkably low mortality rate, $26 \%$ of patients still had moderate to severe GCS scores at discharge. This increased survivability from TBI is seen on the civilian side, as well. ${ }^{32}$

As a result, more patients must ponder their next steps and life after injury. Survivors may face years of disability, a higher risk of neurodegenerative disease, and higher rates of all-cause mortality. ${ }^{35}$ Compounding these hurdles with estimates of the lifelong cost of severe TBI at approximately $\$ 400,000$ per person (approximately $80 \%$ of which stems from disability and lost productivity), the path to recovery for these patients is challenging. ${ }^{9}$ Therapeutic interventions following injury are very limited and are primarily focused on management of intracranial pressure, restoration of cerebral perfusion, and prevention of secondary injury by maintaining homeostasis. ${ }^{21}$ Longterm medical care for these patients consists primarily of rehabilitative services, which have proven beneficial for psychosocial, cognitive, and motor functioning. ${ }^{4,5,29}$ However, rehabilitation resources vary according to state funding and availability. ${ }^{10}$ Providers cite a lack of resources as a significant barrier to rehabilitation. ${ }^{14}$ Poor insurance coverage, limited transportation, low income, and lack of information and transparency have been reported as barriers to rehabilitation access from the patient perspective as well. ${ }^{1,6,30}$ However, these financial and resource issues may not apply to service members.

Much is also left unanswered in the realm of long-term prognostication. The inherent heterogeneity of TBI and consequent difficulties in establishing injury classification schemas make identifying and comparing outcomes difficult. ${ }^{10,28}$ This poor understanding of prognosis translates to difficulties in identifying and administering optimal rehabilitative therapies..$^{10}$ As such, the development of effective interventions is firmly dependent on a better understanding of injury subtype prognosis. Currently, there are 9 open or active clinical trials from the National Institute of Neurological Disorders and Stroke studying TBI, with 3 examining long-term prognosis and outcomes (https:// www.ninds.nih.gov/Disorders/Clinical-Trials/FindNinds-Clinical-Trials).

The demographics reported herein highlight additional challenges facing military physicians in particular. First, local nationals made up the largest demographic group, highlighting the complexity of military medicine in treating a besieged population expressing different beliefs socio-economically, religiously, and practically. Second, because the vast majority of patients treated in the current conflicts are local nationals who are discharged within 24 hours from the military service and observation, the abil- 
ity to determine patient outcome is almost nonexistent. Third, collection of long-term outcomes within the armed services is hindered by the transfer of patients generally within 24 hours of admission and the traditional reliance on 30-day mortality as the primary outcome measure in military reports. ${ }^{11}$

Decompressive craniectomies comprised nearly onequarter of all procedures performed, reflecting the preferential use of surgical decompression for intracranial pressure management in the setting of resource-limited battlefield theaters. ${ }^{2,27}$ Regarding mechanism of injury in this series, $37 \%$ of patients suffered blast injuries and $40 \%$ suffered blunt trauma. Furthermore, our data suggest that many patients evaluated for head injury have only mild deficits on arrival, with $47 \%$ of patients having a GCS score of 13 or greater. But despite this "mild" category of TBI, there is growing concern that these patients are at risk for long-term sequelae of traumatic or concussive injuries, and given their "mild" designation are at risk of being lost to follow-up..$^{12}$ Of additional interest, patients sustaining any comorbid injury in addition to TBI in this series had a significantly higher incidence of pupil nonreactivity at arrival, portending worse long-term outcomes. The literature suggests that comorbid injury is indeed associated with worse outcomes, but this relationship has not yet been fully elucidated. ${ }^{20}$ Given the known detrimental effects of inflammation and ischemia on TBI pathophysiology, it follows that additional sites of bodily injury and blood loss may exact a higher toll on an already taxed nervous system..$^{16}$

There is increasing interest in the identification and long-term outcomes of mild TBI, such as chronic traumatic encephalopathy, with interest in the histopathological and neuropsychiatric effects of brain injury. Psychiatric symptoms such as suicidality and depression are gaining attention as possible sequelae of axonal injury from blast injury as well., ${ }^{72}$ The resurgence of interest in TBI sequelae provides a hopeful opportunity for increased research in TBI pathophysiology, outcome, and treatment. Despite diminishing US involvement in the wars in Afghanistan and Iraq, global conflicts in areas such as Syria, Yemen, Ukraine, and Venezuela continue and remain potential sites for battlefield TBI. The combat theater provides a unique opportunity to systematically evaluate head injury, with practitioners seeing large volumes of patients typically treated at a single institution in a manner not appreciated in the civilian world. Better organization is needed to accurately capture the posttreatment effects in both allied armed services and local nationals, who will probably continue to constitute a substantial proportion of TBI. Increased focus on long-term outcomes and rehabilitative measures is also needed to improve quality of life for patients surviving TBI.

There are several limitations to this paper. First, the results expressed here are limited in the information provided. Demographic, presentation, procedure, and outcome data were prospectively recorded by the senior author, but were not subject to a standardized protocol. Some demographic data are therefore missing or were unavailable, limiting our ability to interpret these findings. Second, the lack of outcome data, which was previously discussed, limits our ability to determine the efficacy of treatment based on presentation or to determine variables that may affect outcome. Third, because this is a demographic report of combat casualties that does not report outcomes, we cannot provide any recommendation on any treatment or the generalizability of outcome to the general population. However, these limitations highlight the need for systemic evaluation and research within military medicine to help shed light on this fascinating but morbid injury.

\section{Conclusions}

We report the demographics, initial and discharge status, and treatment regimens of patients seen by a single USN neurosurgeon treating TBI during the war in Afghanistan. The most common mechanisms of injury were blunt trauma and blast injury, $41 \%$ of patients had comorbid injuries, and $26 \%$ had moderate to severe TBI based on GCS score at discharge. The lack of follow-up data among military neurosurgeons limits the ability to determine short- or long-term outcome. Improvements in reporting and documenting of military patients have the potential to improve our knowledge of TBI and further identify potential variables or treatments that may affect prognosis. The increased survivability from TBI highlights the need for additional research expenditure in the field of neurorehabilitation.

\section{Acknowledgments}

We thank the members of the armed services and their families, as well as healthcare providers in the armed services, for their sacrifice and dedication to our country.

\section{References}

1. Albrecht JS, O'Hara LM, Moser KA, Mullins CD, Rao V: Perception of barriers to the diagnosis and receipt of treatment for neuropsychiatric disturbances after traumatic brain injury. Arch Phys Med Rehabil 98:2548-2552, 2017

2. Bell RS, Mossop CM, Dirks MS, Stephens FL, Mulligan L, Ecker R, et al: Early decompressive craniectomy for severe penetrating and closed head injury during wartime. Neurosurg Focus 28(5):E1, 2010

3. Butler FK: Two decades of saving lives on the battlefield: tactical combat casualty care turns 20. Mil Med 182:e1563e1568, 2017

4. Cicerone KD, Langenbahn DM, Braden C, Malec JF, Kalmar K, Fraas M, et al: Evidence-based cognitive rehabilitation: updated review of the literature from 2003 through 2008. Arch Phys Med Rehabil 92:519-530, 2011

5. Cifu DX, Kreutzer JS, Kolakowsky-Hayner SA, Marwitz JH, Englander J: The relationship between therapy intensity and rehabilitative outcomes after traumatic brain injury: a multicenter analysis. Arch Phys Med Rehabil 84:1441-1448, 2003

6. Dams-O'Connor K, Landau A, Hoffman J, St De Lore J: Patient perspectives on quality and access to healthcare after brain injury. Brain Inj 32:431-441, 2018

7. DeBeer BB, Kimbrel NA, Mendoza C, Davidson D, Meyer EC, La Bash H, et al: Traumatic brain injury, sleep quality, and suicidal ideation in Iraq/Afghanistan era veterans. J Nerv Ment Dis 205:512-516, 2017

8. DuBose JJ, Barmparas G, Inaba K, Stein DM, Scalea T, Cancio LC, et al: Isolated severe traumatic brain injuries sustained during combat operations: demographics, mortality 
outcomes, and lessons to be learned from contrasts to civilian counterparts. J Trauma 70:11-18, 2011

9. Faul M, Wald MM, Rutland-Brown W, Sullivent EE, Sattin RW: Using a cost-benefit analysis to estimate outcomes of a clinical treatment guideline: testing the Brain Trauma Foundation guidelines for the treatment of severe traumatic brain injury. J Trauma 63:1271-1278, 2007

10. Frieden TR, Houry D, Baldwin G: Report to Congress. Traumatic Brain Injury in the United States: Epidemiology and Rehabilitation. Atlanta: Centers for Disease Control and Prevention, 2015

11. Galarneau MR, Woodruff SI, Dye JL, Mohrle CR, Wade AL: Traumatic brain injury during Operation Iraqi Freedom: findings from the United States Navy-Marine Corps Combat Trauma Registry. J Neurosurg 108:950-957, 2008

12. Hasoon J: Blast-associated traumatic brain injury in the military as a potential trigger for dementia and chronic traumatic encephalopathy. US Army Med Dep J (1-17):102-105, 2017

13. Howard JT, Kotwal RS, Santos-Lazada AR, Martin MJ, Stockinger ZT: Reexamination of a battlefield trauma golden hour policy. J Trauma Acute Care Surg 84:11-18, 2018

14. Kreitzer N, Rath K, Kurowski BG, Bakas T, Hart K, Lindsell $\mathrm{CJ}$, et al: Rehabilitation practices in patients with moderate and severe traumatic brain injury. J Head Trauma Rehabil [epub ahead of print], 2019

15. Lehman C: Mechanisms of injury in wartime. Rehabil Nurs 33:192-197, 205, 2008

16. Maas AI, Stocchetti N, Bullock R: Moderate and severe traumatic brain injury in adults. Lancet Neurol 7:728-741, 2008

17. Management of Concussion-Mild Traumatic Brain Injury Working Group: VA/DOD Clinical Practice Guideline For The Management Of Concussion-Mild Traumatic Brain Injury. Washington, DC: Department of Veterans Affairs, 2016

18. Manring MM, Hawk A, Calhoun JH, Andersen RC: Treatment of war wounds: a historical review. Clin Orthop Relat Res 467:2168-2191, 2009

19. Maughon JS: An inquiry into the nature of wounds resulting in killed in action in Vietnam. Mil Med 135:8-13, 1970

20. Mollayeva T, Xiong C, Hanafy S, Chan V, Hu ZJ, Sutton M, et al: Comorbidity and outcomes in traumatic brain injury: protocol for a systematic review on functional status and risk of death. BMJ Open 7:e018626, 2017

21. Norisue Y, Fujimoto Y, Nakagawa K: Preliminary guidelineand pathophysiology-based protocols for neurocritical care. J Intensive Care 6:45, 2018

22. O'Connell KM, Littleton-Kearney MT, Bridges E, Bibb SC: Evaluating the Joint Theater Trauma Registry as a data source to benchmark casualty care. Mil Med 177:546-552, 2012

23. Oh JS, Tubb CC, Poepping TP, Ryan P, Clasper JC, Katschke AR, et al: Dismounted blast injuries in patients treated at a role 3 military hospital in Afghanistan: patterns of injury and mortality. Mil Med 181:1069-1074, 2016

24. Okie S: Traumatic brain injury in the war zone. N Engl J Med 352:2043-2047, 2005

25. Pikoulis EA, Petropoulos JCB, Tsigris C, Pikoulis N, Leppäniemi $\mathrm{AK}$, Pavlakis $\mathrm{E}$, et al: Trauma management in ancient Greece: value of surgical principles through the years. World J Surg 28:425-430, 2004
26. Pruitt BA Jr: Combat casualty care and surgical progress. Ann Surg 243:715-729, 2006

27. Ragel BT, Klimo P Jr, Martin JE, Teff RJ, Bakken HE, Armonda RA: Wartime decompressive craniectomy: technique and lessons learned. Neurosurg Focus 28(5):E2, 2010

28. Rosenfeld JV, Maas AI, Bragge P, Morganti-Kossmann MC, Manley GT, Gruen RL: Early management of severe traumatic brain injury. Lancet 380:1088-1098, 2012

29. Sarajuuri JM, Kaipio ML, Koskinen SK, Niemelä MR, Servo AR, Vilkki JS: Outcome of a comprehensive neurorehabilitation program for patients with traumatic brain injury. Arch Phys Med Rehabil 86:2296-2302, 2005

30. Schulz-Heik RJ, Poole JH, Dahdah MN, Sullivan C, Adamson MM, Date ES, et al: Service needs and barriers to care five or more years after moderate to severe TBI among veterans. Brain Inj 31:1287-1293, 2017

31. Sharrock AE, Remick KN, Midwinter MJ, Rickard RF: Combat vascular injury: Influence of mechanism of injury on outcome. Injury 50:125-130, 2019

32. Stein SC, Georgoff P, Meghan S, Mizra K, Sonnad SS: 150 years of treating severe traumatic brain injury: a systematic review of progress in mortality. J Neurotrauma 27:13431353,2010

33. Swanson TM, Isaacson BM, Cyborski CM, French LM, Tsao JW, Pasquina PF: Traumatic brain injury incidence, clinical overview, and policies in the US military health system since 2000. Public Health Rep 132:251-259, 2017

34. Wilson L, Stewart W, Dams-O'Connor K, Diaz-Arrastia R, Horton L, Menon DK, et al: The chronic and evolving neurological consequences of traumatic brain injury. Lancet Neurol 16:813-825, 2017

\section{Disclaimer}

The views and opinions expressed in this article are those of the authors and do not represent the official views of the United States Navy, Department of Defense, or the United States Government.

\section{Disclosures}

The authors report no conflict of interest concerning the materials or methods used in this study or the findings specified in this paper.

\section{Author Contributions}

Conception and design: Park. Acquisition of data: Park. Analysis and interpretation of data: Patel, Taylor. Drafting the article: Patel, Taylor. Critically revising the article: all authors. Reviewed submitted version of manuscript: all authors. Approved the final version of the manuscript on behalf of all authors: Park. Statistical analysis: Patel.

\section{Correspondence}

Min S. Park: University of Virginia Health System, Charlottesville, VA.mp2tq@virginia.edu. 